\title{
Factores ecológicos y su incidencia en los ecosistemas del chame (dormitator latifrons) en la Segua de Canuto cantón Chone - Ecuador.
}

\section{Ecological factors and their impact on ecosystems in the Chame (Dormitator latifrons) in La Segua Marsh of Canute canton Chone - Ecuador.}

Miguel Angel Osejos Merino. ${ }^{1}$ Martin Verisimo Merino Conforme. ${ }^{2}$, Julio Javier Jaramillo Véliz. ${ }^{3} \&$ Monserrate Cristina Merino Conforme. ${ }^{4}$

Recibido: 13-12-2017 / Revisado: 09-02-2018 Aceptado: 12-03-2018/ Publicado: 01-04-2018

\begin{abstract}
.
DOI: https://doi.org/10.33262/cienciadigital.v2i2.92

This investigation entitled: "Ecological factors and their incidence on the ecosystems of the chame (Dormitator latifrons) in the Segua de Canuto canton Chone - Ecuador" was carried out during the period 2017. In Ecuador, one of the most important is the Segua Wetland, located in the canton Chone of the province of Manabí, the same that constitutes an important source of resources that generates social and economic benefits for the inhabitants of the area for being propitious for the reproduction of the Chame (Dormitator latifrons); activities that generate affectations in this ecosystem. The methodology used for its development was based on the application of techniques and instruments such as observation, surveys and field tests, for the realization of the investigation temperature and $\mathrm{pH}$ samples were taken in the center of the Segua de Canuto of the canton Chone the days to make the samples were on Monday and Thursday for a period of 2 months: October and November, the schedules that were established for the sampling were from 7:30 to 8:00, from 12:30 a.m. 13:00 and from 17:00 to 17:30, with intervals of 3 minutes each for the measurement of temperature and $\mathrm{pH}$, with the found values a general average was made for each day which was used for demonstration
\end{abstract}

\begin{tabular}{|c|c|c|c|c|c|c|c|c|}
\hline $\begin{array}{c}{ }^{1} \text { Docente de la Universidad } \\
\text { miguel.osejos@unesum.edu.ec }\end{array}$ & Estatal & del & Sur & de & Manabí, & UNESUM, & Manabí, & Ecuador \\
\hline $\begin{array}{l}{ }^{2} \text { Docente de la Universidad } \\
\text { martinmerinoconforme } @ \text { yahoo.es }\end{array}$ & Estatal & del & Sur & de & Manabí, & UNESUM, & Manabí, & Ecuador \\
\hline $\begin{array}{c}\text { 30ocente de la Universidad } \\
\text { julio.jaramillo@unesum.edu.ec }\end{array}$ & Estatal & del & Sur & de & Manabí, & UNESUM, & Manabí, & Ecuador \\
\hline $\begin{array}{l}{ }^{4} \text { Docente de la } \\
\text { monserratemerino }\end{array}$ & Estatal & del & Sur & de & Manabí, & UNESUM, & Manabí, & Ecuador \\
\hline
\end{tabular}


of the study, analysis of the samples taken in the wetland for 28 days showed that the $\mathrm{pH}$ level was within the optimum average range; while the temperature was found at ideal levels mentioned above only in three days. It should be noted that in the rest of the days in which the analyzes were carried out, for the temperature the results surpassed the optimum average range for the chame ecosystem, which shows that both the development of the economic activities and the climatic changes generated in the area have a negative impact on the chame ecosystem.

Keywords: Ecological factors, Chame, Segua de Canuto, canton Chone.

\section{Resumen.}

Esta investigación titulada: "Factores ecológicos y su incidencia en los ecosistemas del chame (Dormitator latifrons) en la Segua de Canuto cantón Chone - Ecuador" se realizó durante el periodo 2017. En Ecuador, uno de los más importantes es el Humedal la Segua, ubicado en el cantón Chone de la provincia de Manabí, el mismo que constituye una fuente importante de recursos que genera beneficios sociales y económicos para los habitantes de la zona por ser propicio para la reproducción del Chame (Dormitator latifrons); actividades que generan afectaciones en este ecosistema. La metodología empleada para su desarrollo se basó en la aplicación de técnicas e instrumentos como la observación, las encuestas y las pruebas de campo, para la realización de la investigación se tomaron muestras de temperatura y $\mathrm{pH}$ en el centro de la Segua de Canuto del cantón Chone los días a realizar la toma de muestras fueron los lunes y jueves por un lapso de 2 meses: octubre y noviembre, los horarios que se establecieron para la toma de muestras fueron de 7:30 a 8:00, de 12:30 a 13:00 y de 17:00 a 17:30, con intervalos de 3 minutos cada uno para la medición de la temperatura y $\mathrm{pH}$, con los valores encontrados se realizó un promedio general para cada día la cual se utilizó para demostración del estudio, los análisis de las muestras tomadas en el humedal durante 28 días demostraron que el nivel de $\mathrm{pH}$ se encontró dentro del rango promedio óptimo; mientras que la temperatura se encontró en niveles ideales antes mencionados únicamente en tres días. Cabe recalcar que en el resto de los días en el que se realizaron los análisis, para la temperatura los resultados sobrepasaron el rango promedio óptimo para el ecosistema del chame, lo cual demuestra que tanto el desarrollo de las actividades económicas como los cambios climáticos que se generan en la zona tienen un impacto negativo en el ecosistema del chame.

Palabras Claves: Factores ecológicos, Chame, Segua de Canuto, cantón Chone.

\section{Introducción.}

Según Haz Alvarado \& Arias Palacios (2002) el cultivo de chame en el Ecuador presenta ventajas indiscutibles frente a otras especies en aspectos como el biológico, técnico y económico ya que es una especie de fácil adaptación que no requiere de mayores cuidados, con alta resistencia a enfermedades; además de su alto valor proteico y su buen sabor. Su alta productividad en la costa ecuatoriana, especialmente en Manabí ha generado una sobreexplotación de esta especie en sus 
áreas de reproducción natural, los humedales, acciones que están generando impactos significativos que deben ser estudiados.

En un estudio realizado por Ortega Granda (2016) denominado "Análisis del comercio internacional del Chame (Dormitator latifrons, Richardson, 1844) y su impacto sobre sus poblaciones silvestres en el Ecuador: Propuesta de inclusión en CITES "se determinó que la especie (Dormitator latifrons) se encuentra catalogada actualmente bajo la categoría (EN) en peligro, esto como resultado del análisis del Método de Evaluación del Grado de Amenaza (MEGA) donde se analizan diferentes variables entre las que constan la presión que ejerce el comercio internacional sobre esta especie, y otras variables más.

En base a lo anterior y de la mano de la evidente problemática existente en relación con la reproducción y crías de chame en sus hábitats naturales, y los riesgos que estas actividades representan para la sostenibilidad de los humedales y el desarrollo de la vida de la especie Dormitator latifrons por el impacto en los factores ecológicos como el $\mathrm{pH}$ y la temperatura del humedal, surgió la interrogante científica ¿cuáles son los impactos de los factores Ecológicos que incide en los ecosistemas del Chame en la Segua de Canuto Cantón Chone?, para la cual se propuso como hipótesis que el Monitoreo de los factores ecológicos permitiría la determinación de los ecosistemas del Chame en la Segua de Canuto Cantón Chone, dando con ello, la pauta para la evaluación y determinación del problema encontrado.

Con la finalidad de encaminar esta investigación hacia la comprobación eficiente y veraz de la hipótesis, se estableció como objetivo general determinar el impacto de los factores ecológicos en los ecosistemas del Chame en la Segua de Canuto Cantón Chone, el mismo que se alcanzó por medio del cumplimento de objetivos específicos como evaluar las principales causas del impacto de los factores ecológicos en los ecosistemas del chame en el Cantón e identificar los niveles de los factores abióticos: temperatura y Potencial de hidrogeno $(\mathrm{pH})$ en los ecosistemas del chame en el Cantón Chone y por último se estableció como objetivo específico el elaborar una propuesta de control en el impacto de los factores ecológicos en los ecosistemas del Chame en La Segua del Cantón Chone, como alternativa de solución a la problemática.

\section{Marco teórico.}

\subsection{Factores ecológicos del chame.}

\subsubsection{Suelo.}

Se puede decir que el suelo es un recurso indispensable para la vida, pues permite el desarrollo de las plantas, los animales y el hombre. Las diversas definiciones más contemporáneas del suelo se caracterizan por integrar en ellas sus propiedades físicas, químicas y biológicas, además de su capacidad de ser sostenibles, producir alimentos sanos y mitigar la polución medioambiental, pues su explotación frecuente e indiscriminada requiere la consideración de todos estos aspectos. 
El Comité para la Salud del Suelo de la Soil Science Society of America establece que la salud del suelo debe ser medida por medio de variables que permitan evaluar su condición ya que un suelo saludable contribuye al funcionamiento de los ecosistemas dentro de sus límites naturales, a la sostenibilidad de plantas y animales, al mejoramiento y mantenimiento de la calidad del agua y del aire, además de contribuir al cuidado de la salud humana y del hábitat en general (Gavino Arias, 2017).

En los humedales los suelos identificados se clasifican en gleysoles, arenosoles, fluviosoles y solonchaks, ya que contienen materiales arenosos, muy permeables; se forman a partir de materiales aluviales recientes aportados por ríos y contienen abundancia de sales; por lo que su textura dominante es franco-arcillosa (Instituto Geográfico Nacional, s.f.).

El suelo del humedal La Segua presenta como características principales que es plano, con bajíos y de pendientes reducidas por lo que su drenaje es lento; se encuentra inundado de manera permanente, inclusive en verano y en invierno, los niveles de agua aumentan, cubriendo los suelos llanos; por lo tanto el suelo de esta zona se considera como franco arenoso, limoso y/o arcilloso limoso, profundo y con depósitos fluviales finos de sedimentos recientes (Arteaga Sabando, 2012). Para la reproducción de chame en cautiverio, el suelo de las piscinas debe ser arcilloso y mantener diferentes niveles de agua que sean muy parecidos a las áreas de reproducción natural y así los peces puedan mantener su cabeza fuera del agua y capturar oxígeno para el intercambio gaseoso que les permite sobrevivir por varias horas fuera del agua (Lascano Freire, 2000).

\subsubsection{Agua, temperatura y $\mathrm{pH}$.}

El chame es un pez cuya presencia prevalece en el agua dulce, lo que genera muchas opciones de lugares donde puede cultivarse y criarse, pues se pueden emplear pozas, estanques, canales, piscinas, como fuentes adicionales a los humedales naturales.

$\mathrm{Su}$ alta adaptabilidad y capacidad de supervivencia le permiten resistir a las variaciones de su hábitat, donde se incluyen factores como temperatura, ph, salinidad, entre otras. Sin embargo, a pesar de esta característica es importante que para su reproducción eficiente en los criaderos se tenga en cuenta que además de que la fuente de agua debe ser abundante y de buena calidad.

La salinidad estandarizada debe ser de hasta $15 \mathrm{ppt}$, las condiciones de oxígeno deben ser desde 2.0 ppm en adelante para asegurar su óptimo desarrollo (Jiménez Marmolejo \& Espín Novoa, 2010).

\subsubsection{Temperatura del Agua.}

Para el cultivo de Chame es necesaria una temperatura que fluctúe entre 21 a $30^{\circ} \mathrm{C}$. Los cambios de temperatura afectan directamente la tasa metabólica, mientras mayor sea la temperatura, mayor será la tasa metabólica aumentando el consumo de oxígeno. (Rodriguez, 1994)

\subsubsection{Potencial de Hidrogeno del Agua.}


De acuerdo a Nava (2008), el cultivo de chame requiere un pH que varía desde 6,4 a 9,4 esto favorece el desarrollo de la productividad natural del hábitat; mientras más estable permanezca el $\mathrm{pH}$, mejores condiciones se propiciarán para la productividad natural la misma que constituye una fuente importante de alimento.

Según indica (Peters, 2015). La contaminación acústica se define como la presencia en el ambiente de ruidos o vibraciones, cualquiera que sea el emisor acústico que los origine, que impliquen molestia, riesgo o daño para las personas, para el desarrollo de sus actividades o para los bienes de cualquier naturaleza, o que causen efectos significativos sobre el medio ambiente.

\subsection{Chame (Dormitator latifrons) Características taxonómicas y fisionómicas.}

El Chame es un pez típico de los estuarios que presenta características como resistencia a variaciones significativas de salinidad y temperatura, sobrevivencia en ambientes acuáticos con deficiencia de oxígeno disuelto, e incremento en la concentración de hemoglobina en ambientes de poca oxigenación. (Sandoval, Madrigal, Escalera, \& Medina, 2014)

Gráfico 1. Chame (Dormitator latifrons).

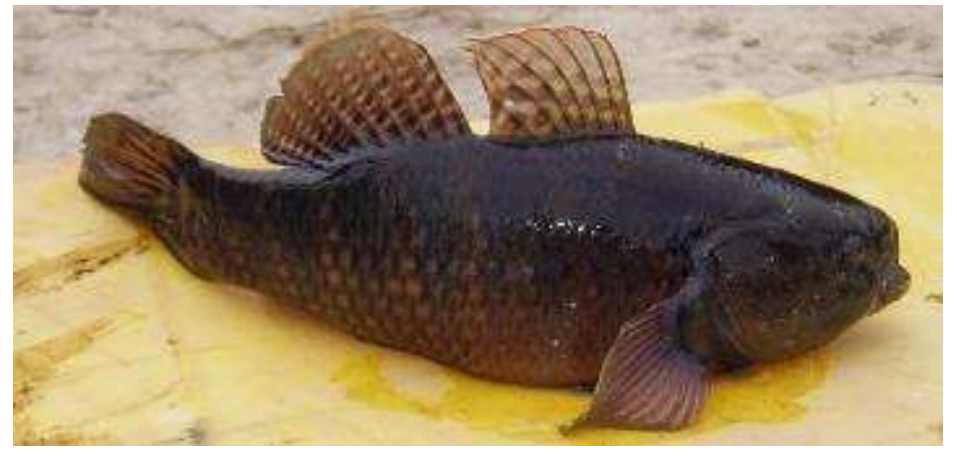

Fuente: (EcoCostas, 2006).

Fisionómicamente este pez se caracteriza por tener un cuerpo corto y robusto, ligeramente comprimido, con una coloración azul verdoso oscuro (puede tener un peso de una a tres libras, su dimensión va desde los 20 hasta los $30 \mathrm{~cm}$.); su cabeza es ancha, tiene 4 barras obscuras irregulares por detrás del ojo y una barra oblicua a continuación, el maxilar llega al margen anterior de la órbita, tiene de 33 - 35 escamas en una serie longitudinal, y aletas pares con puntuaciones obscuras; dorsal con manchas obscuras regulares; caudal con las membranas interradiales muy obscuras.

El nombre científico de este pez es Dormitator latifrons y según Richardson (1844) a nivel taxonómico se ubica dentro de la familia Eleotridae. El tiempo de producción del Chame es de un año aproximadamente cuando no se le suministra alimentación suplementaria, aunque esto varía de acuerdo a la densidad de siembra y la calidad del agua (EcoCostas, 2006). 
En esta especie de pez el macho presenta una coloración rojiza y la hembra un azul verdoso obscuro, por otra parte generalmente adoptan aptitudes de reposo permaneciendo en el fondo del agua $\sin$ efectuar movimientos. También se los denomina como estuarios ya que pueden desarrollarse en hábitats de agua salada como de agua dulce. Es un pez herbívoro que se alimenta del detritus natural de su hábitat. (Haz, 2002)

\subsubsection{Distribución natural y artificial.}

De acuerdo a Haz (2002) el Chame (Dormitator latifrons) también conocido como fat sleeper, puyeque, popoyote o chalaco, en un pez cuya distribución natural va desde California, Estados Unidos de Norte América, hasta las costas de Perú, es cultivado a mediana escala en Ecuador y existe interés en México y Nicaragua para desarrollar su producción por acuicultura.

En época de invierno, los alevines de chames abundan en las orillas de los ríos y se trasladan por las corrientes hacia las ciénagas o lagunas de manera natural, lo que se conoce como chameras de cultivo artesanal pues no necesitan ser sembrados para ser aprovechados económicamente cuando alcanzan su tamaño comercial.

En el Ecuador el cultivo artificial de chame se produce cuando se lo cultiva en piscinas de arcilla o en jaulas y en el Ecuador esta práctica se produce en las provincias de Esmeraldas (San Lorenzo y Muisne), Manabí (Chone y Tosagua), en Santa Elena y en Guayas (Guasmo, Yaguachi y Guayaquil). (Rodríguez Montes de Oca, y otros, 2012).

\subsubsection{Distribución del chame en la provincia de Manabí .}

En Manabí existen muchos lugares naturales de reproducción y crecimiento del chame, donde las zonas de reproducción y/o desove se ubican en las áreas de influencia del estuario de Chone, como Larrea, Simbocal, Barquero y en las cercanías a las camaroneras que se encuentran en el estuario de Chone; mientras que el humedal La Segua es reconocido como la zona de principal crecimiento de este pez.

Se estima que como el chame es un pez que se desarrolla y encuentra en aguas dulces y salobres, esta especie es abundante en estas zonas debido a que las hembras llegan a estos sitios atraídas por la salinidad de las aguas para desovar y una vez cumplido este proceso, las especies avanzan río arriba y se establecen en el humedal para, en el caso de los alevines completar su crecimiento y los adultos por su parte, para esperar a que llegue la temporada de migración para el inicio de un nuevo ciclo de reproducción y desove (EcoCostas, 2006).

\subsection{Generalidades de La Segua de Canuto cantón Chone.}

\subsubsection{Cantón Chone.}


El cantón Chone se encuentra ubicado en la zona norte de la Provincia de Manabí y cuenta con una superficie de 3.570,6 kilómetros cuadrados, posee un clima cálido seco en verano y cálido lluvioso en la época de invierno.

Su cabecera cantonal es la ciudad de Chone y está conformado por dos parroquias urbanas que son Chone y Santa Rita y siete parroquias rurales que son Canuto, Ricaurte, Eloy Alfaro, Boyacá, Convento, San Antonio y Chibunga. La población de este cantón es de 126.491 habitantes (Gobierno Provincial de Manabí, 2016).

Chone limita al norte con la provincia de Esmeraldas y el cantón Pedernales; al sur con los cantones de Pichincha, Bolívar y Tosagua; al este con El Carmen, Flavio Alfaro y la provincia de Los Ríos y, al oeste con los cantones Sucre, Junín, Jama y Pedernales. (Zambrano, 2014)

\subsubsection{Parroquia Canuto del Cantón Chone.}

La parroquia rural Canuto se encuentra situada al sur del Cantón Chone, en la Provincia de Manabí, Ecuador y su nombre aparentemente se origina por la devoción que los primeros pobladores profesaban al rey danés Canuto IV. Su ubicación estratégica le facilita el acceso a centros urbanos como la cabecera cantonal Chone y Calceta que pertenece al cantón Bolívar. (GAD Parroquial Canuto, 2015)

Canuto se fundó el 13 de agosto de 1862 e inicialmente perteneció a la jurisdicción de Tosagua, luego pasó a formar parte del cantón Rocafuerte y finalmente, en 1897 y al crearse el cantón Chone se convirtió en parte de él, siendo la parroquia más antigua de este cantón.

\subsubsection{Humedal La Segua.}

La Segua es un humedal de agua dulce formado por una ciénaga central inundada la mayor parte del tiempo y una planicie extensiva inundable en la estación lluviosa que se da entre los meses de diciembre y abril. El suelo de este humedal se caracteriza por ser arenoso, limoso y/o arcillo-limoso, profundo con depósitos sedimentarios fluviales finos recientes. La profundidad de la ciénaga puede alcanzar un promedio de $1.27 \mathrm{~m}$. (Valarezo \& Quevedo, 2009)

En cuanto al agua que compone este humedal, se puede decir que presenta una calidad media, con presencia de coliformes fecales y sólidos totales, además de un bajo porcentaje de oxígeno disuelto.

En la Segua existe una gran diversidad de organismos en donde destaca una alta densidad faunística conformada por 12 especies de peces, dos especies de camarones de río, tortugas del género Chelydra y 164 especies de aves de las cuales 22 son migratorias y 63 son acuáticas). Su flora está representada por 27 familias y 33 especies silvestres; y durante la estación lluviosa predominan las plantas acuáticas, especialmente los "lechuguines" (Eichhornia crassipes) (Ministerio del Ambiente, 2015).

\section{Metodología.}




\section{Ubicación Geográfica de la Investigación.}

El presente trabajo de investigación se llevó a cabo en La ciénaga La Segua se encuentra en la provincia de Manabí, Parroquia San Antonio en Canuto del Cantón Chone, aproximadamente a $11.5 \mathrm{~km}$ al suroeste de la ciudad de Chone, se ubica en la parte alta del estuario del Río Chone, favorecida por la confluencia de los ríos Carrizal y Chone. (Valarezo \& Quevedo, 2009)

Altitud: (media y/o máx. y mín.) 5 m.s.n.m.

Área: (en hectáreas) 1745 hectáreas

Durante la estación seca, la planicie de inundación está repleta de hierbas y el espejo de agua se reduce a aproximadamente 525 hectáreas, con una profundidad promedio de $67 \mathrm{~cm}$. Alrededor de la ciénaga se encuentran cuatro centros poblados: San Antonio, La Segua, La Sabana y Larrea, con una población estimada de 1.700 personas.

Las reservas de agua subterránea renovables anualmente en la provincia alcanzan un valor de 3000 $\mathrm{hm}^{3}$, distribuidas espacialmente en las Zonas de Desarrollo Norte (260 hm3), Central $\left(385 \mathrm{hm}^{3}\right)$, Suroeste $\left(34 \mathrm{hm}^{3}\right)$, Oriental $\left(1908 \mathrm{hm}^{3}\right)$ y Sur $\left(413 \mathrm{hm}^{3}\right)$. Esta distribución coincide con el hecho que en donde existe menor población concentrada es donde hay mayor reserva de agua subterránea, caso de la Zona Oriental que cuenta con el $64 \%$ de las reservas de toda la provincia. Sin embargo, donde hay la mayor población y los mejores suelos agrícolas, Zona Central, tan sólo se cuenta con el $13 \%$ de las reservas anuales renovables.

El clima predominante es el cálido seco en época seca, que va desde junio hasta noviembre, en épocas normales; y el cálido lluvioso en época lluviosa, que va de diciembre a mayo. En época seca los vientos modifican el clima y su temperatura oscila entre $\operatorname{los} 23$ y $28^{\circ} \mathrm{C}$, mientras que en época lluviosa alcanza $\operatorname{los} 34^{\circ} \mathrm{C}$, considerándose uno de los climas más inestables y desequilibrados de las regiones costeras del Pacifico sudamericano. (Valarezo \& Quevedo, 2009) 


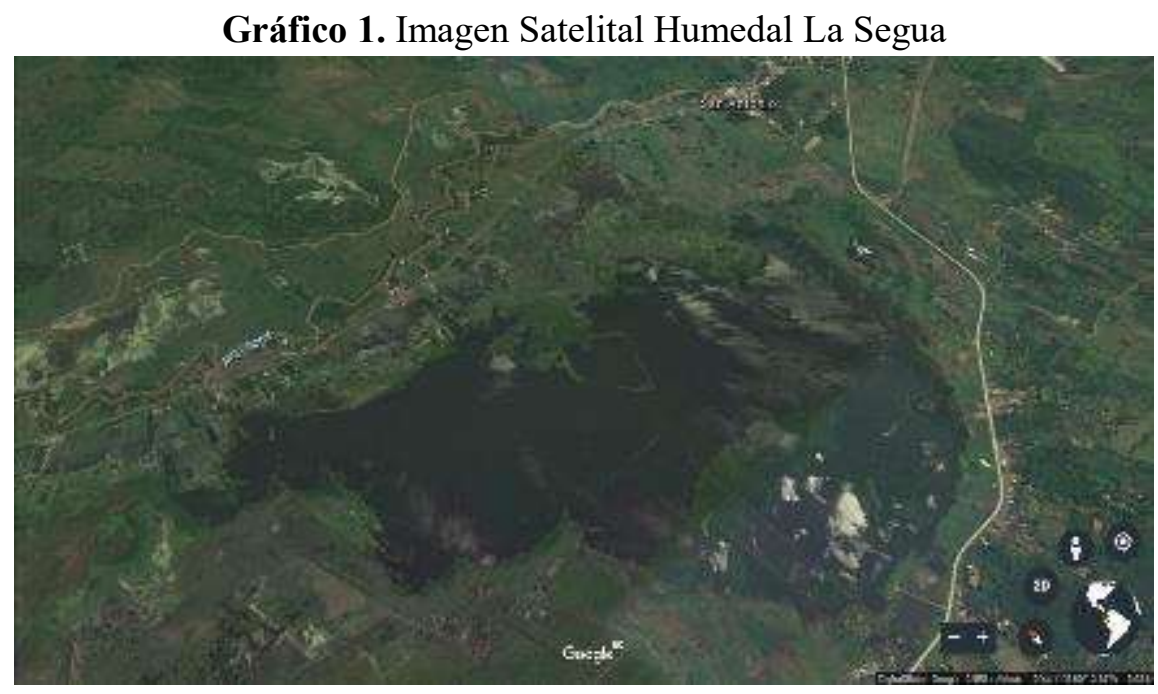

Fuente: Google Earth

La presente investigación fue desarrollada mediante el método de observación previo a la determinación del lugar y aplicación del instrumento de medición, tabulación e interpretación de resultados. Además se realizaron encuestas.

Para el desarrollo de esta investigación se utilizó la investigación no experimental de índole descriptiva, la cual permitió observar y describir el comportamiento de las variables de estudio sin la necesidad de influir sobre estos, la cual está respaldada por medio de acciones que permitieron describir las características de los factores ecológicos existentes en La Segua de Canuto cantón Chone y su influencia en los ecosistemas del chame (Dormitator latifrons).

La metodología permitió recabar datos que indican una relación directa de la variación de los factores ecológicos existentes en La Segua como la temperatura y el $\mathrm{pH}$ con la variación de los ecosistemas del chame.

Para la medición de $\mathrm{pH}$ y temperatura se utilizó un equipo de lectura multiparámetro portatil de marca Hahc, el cual utiliza tres sondas con electrodos una para el $\mathrm{pH}$, otra para la temperatura y la tercera que daba varios parámetros de lecturas, la cual se calibro de acuerdo a la medición que se necesitaba realizar.

Para la realización de la investigación se tomaron muestras de temperatura y $\mathrm{pH}$ en el centro de La Segua de Canuto del cantón Chone. Los días a realizar la toma de muestras fueron los lunes y jueves por un lapso de 2 meses: octubre y noviembre, los horarios que se establecieron para la toma de muestras fueron de 7:30 a 8:00, de 12:30 a 13:00 y de 17:00 a 17:30, con intervalos de 3 minutos cada uno para la medición de la temperatura y $\mathrm{pH}$. Con los valores encontrados se realizó un promedio general para cada día la cual se utilizó para la demostración del estudio.

\section{Resultados}


1. ¿Conoce usted acerca del chame?

Tabla 1 Conocimiento acerca del chame.

\begin{tabular}{ccc}
\hline RESPUESTA & FRECUENCIA & PORCENTAJE \\
\hline SI & 384 & $100 \%$ \\
NO & 0 & $0 \%$ \\
TOTAL & 384 & $100 \%$ \\
\hline
\end{tabular}

Fuente: Habitantes de la parroquia Canuto del cantón Chone Elaboración propia.

Gráfico 3 Conocimiento acerca del chame.

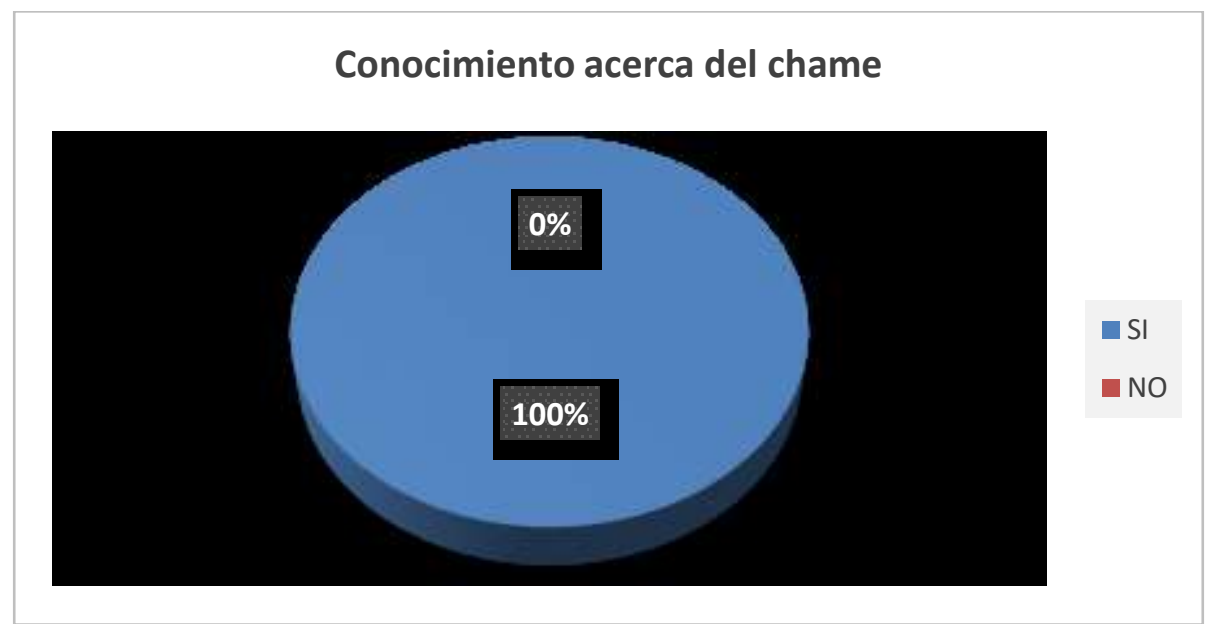

Fuente: Habitantes de la parroquia Canuto del cantón Chone

Elaboración propia.

Una vez analizado e interpretado los resultados según tabla $\mathrm{N}^{\circ} 1$ y grafico $\mathrm{N}^{\circ} 3$ de $\operatorname{los} 384$ encuestados respondieron que si conocen acerca del chame, lo que corresponde al 100\%. Los habitantes respondieron todo afirmativo por motivo que al ser Chone uno de los cantones que se dedican a la producción de chame, es necesario que cada una de las personas que conforman este cantón conozcan de manera integral aspecto generales sobre este patrimonio alimentario.

\section{2. ¿Cree usted que la incidencia de los factores ecológicos afectan al chame?}

Tabla 2 Incidencia de los factores ecológicos en el chame

\begin{tabular}{ccc} 
RESPUESTA & FRECUENCIA & PORCENTAJE \\
\hline SI & 384 & $100 \%$ \\
NO & 0 & $0 \%$
\end{tabular}


Fuente: Habitantes de la parroquia Canuto del cantón Chone Elaboración propia

Gráfico 4 Incidencia de los factores ecológicos en el chame

\section{Incidencia de los factores ecológicos en el chame}

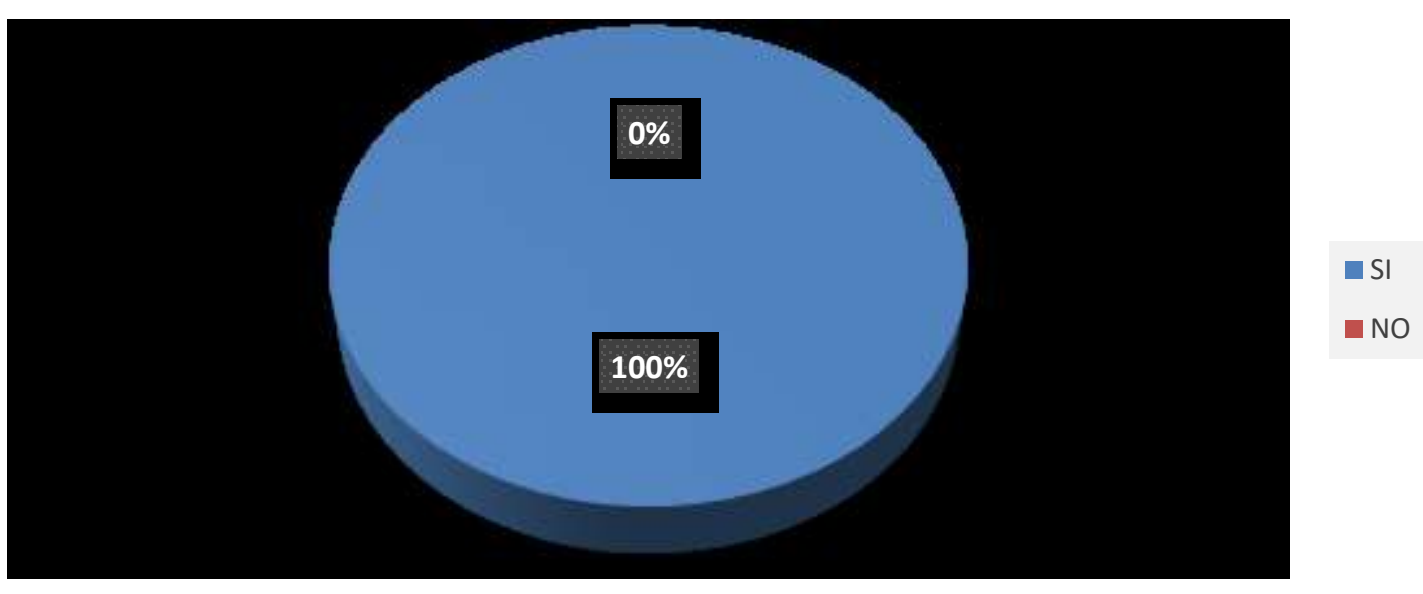

Fuente: Habitantes de la parroquia Canuto del cantón Chone

Elaboración propia

Una vez analizado e interpretado los resultados según tabla $\mathrm{N}^{\circ} 2$ y grafico $\mathrm{N}^{\circ} 4$ de $\operatorname{los} 384$ encuestados contestaron que si incide los factores ecológicos al chame, lo que corresponde al 100\%. Como todos los seres vivos los factores ecológicos pueden influenciar de manera directa al crecimiento del chame, ya que al exponerse a un ambiente no gradual para su habitad puede asumirse que tendrá ciertos riesgos en la especie, hasta provocar que se encuentren en amenaza y por lo consiguiente la disminución del pez.

3. ¿Cree usted que el cambio brusco de temperatura afecta en el crecimiento del chame?

Tabla 3 Temperatura influencia en el crecimiento del chame

\begin{tabular}{ccc}
\hline RESPUESTA & FRECUENCIA & PORCENTAJE \\
\hline SI & 380 & $100 \%$ \\
NO & 0 & $0 \%$ \\
TOTAL & 384 & $100 \%$ \\
\hline
\end{tabular}

Fuente: Habitantes de la parroquia Canuto del cantón Chone Elaboración propia. 
Gráfico 5 Temperatura influencia en el crecimiento del chame.

Temperatura influencia en el crecimiento del chame

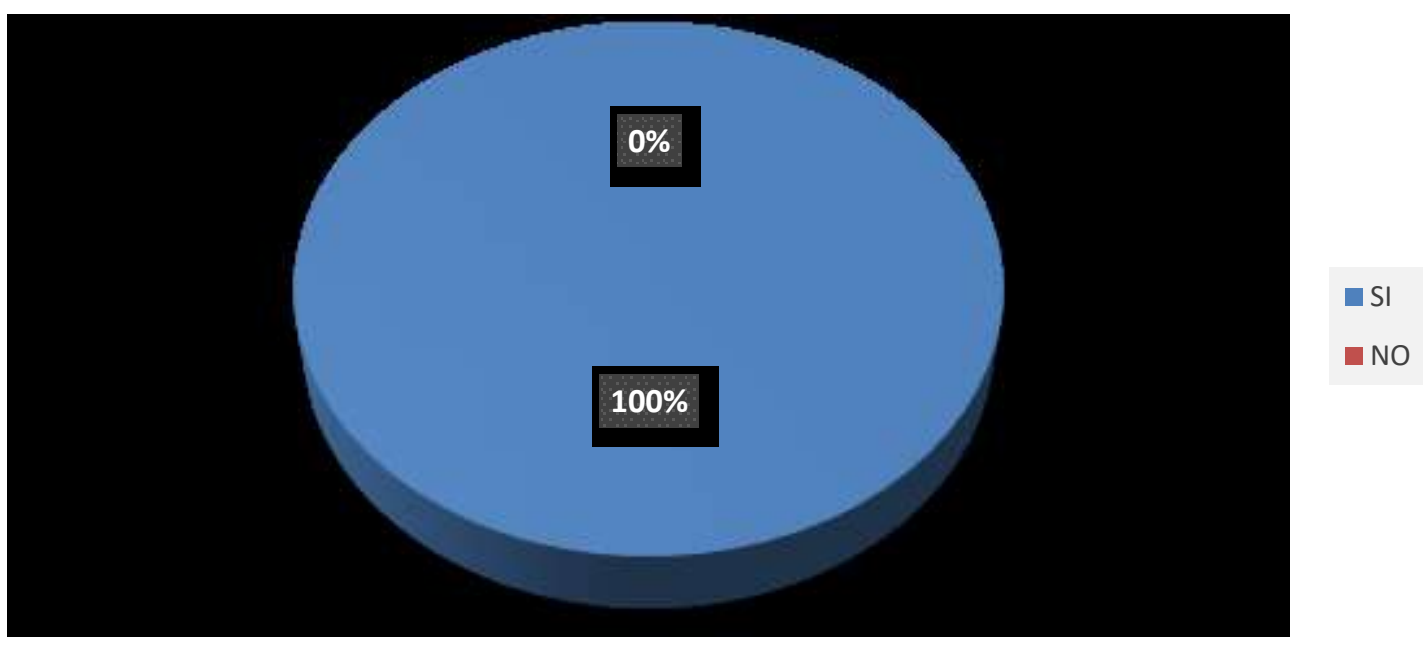

Fuente: Habitantes de la parroquia Canuto del cantón Chone.

Elaboración propia.

Analizado e interpretado los resultados según tabla $\mathrm{N}^{\circ} 3$ y grafico $\mathrm{N}^{\circ} 5$ de los 384 encuestados respondieron que la Temperatura si influye en el crecimiento del chame lo que equivale al $100 \%$. En lo referente que se mencionaba anteriormente las altas o bajas temperaturas del ambiente pueden provocar ciertos daños en la especie del chame, y esto han observado los habitantes cuando están en captura de este apreciado pez, donde cada cierta temporada existen variaciones en la cantidad del pescado por este problema.

4. ¿Cree usted que el cambio de los niveles de $\mathrm{pH}$ afecta en el crecimiento del chame?

Tabla 4 pH y su afectación al crecimiento del chame.

\begin{tabular}{ccc}
\hline RESPUESTA & FRECUENCIA & PORCENTAJE \\
\hline SI & 380 & $100 \%$ \\
NO & 0 & $0 \%$ \\
TOTAL & 384 & $100 \%$ \\
\hline
\end{tabular}


Fuente: Habitantes de la parroquia Canuto del cantón Chone

Elaboración propia.

Gráfico $6 \mathrm{pH}$ y su afectación al crecimiento del chame.

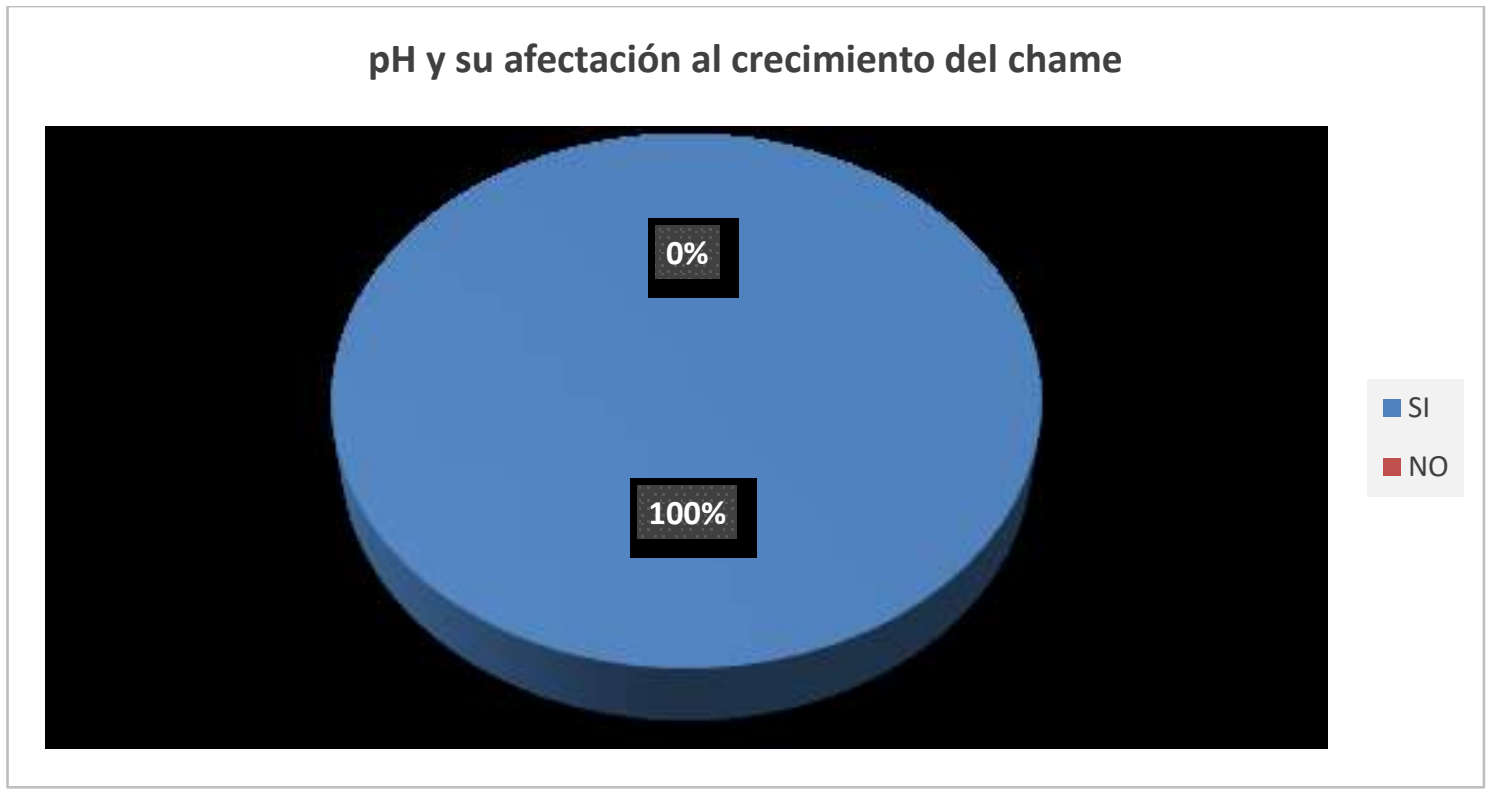

Fuente: Habitantes de la parroquia Canuto del cantón Chone.

Elaboración propia.

Una vez analizado e interpretado los resultados según tabla $\mathrm{N}^{\circ} 4$ y grafico $\mathrm{N}^{\circ} 6$ de $\operatorname{los} 384$ encuestados el 100\% contestaron que el cambio de los niveles de $\mathrm{pH}$ si afecta en el crecimiento del chame. La población encuestada al poseer un conocimiento empírico y en lo que ha escuchado por los diferentes investigadores que llegan al humedal, han establecido que los niveles de $\mathrm{pH}$ afecta directamente al crecimiento del chame.

5. ¿Cree usted que los ecosistemas del chame están siendo afectados por la variabilidad de los factores ecológicos?

Tabla 5 Afectación de los ecosistemas del chame por factores ecológicos.

\begin{tabular}{ccc}
\hline RESPUESTA & FRECUENCIA & PORCENTAJE \\
\hline SI & 380 & $100 \%$
\end{tabular}


Fuente: Habitantes de la parroquia Canuto del cantón Chone

Elaboración propia.

Gráfico 7. Afectación de los ecosistemas del chame por factores ecológicos.

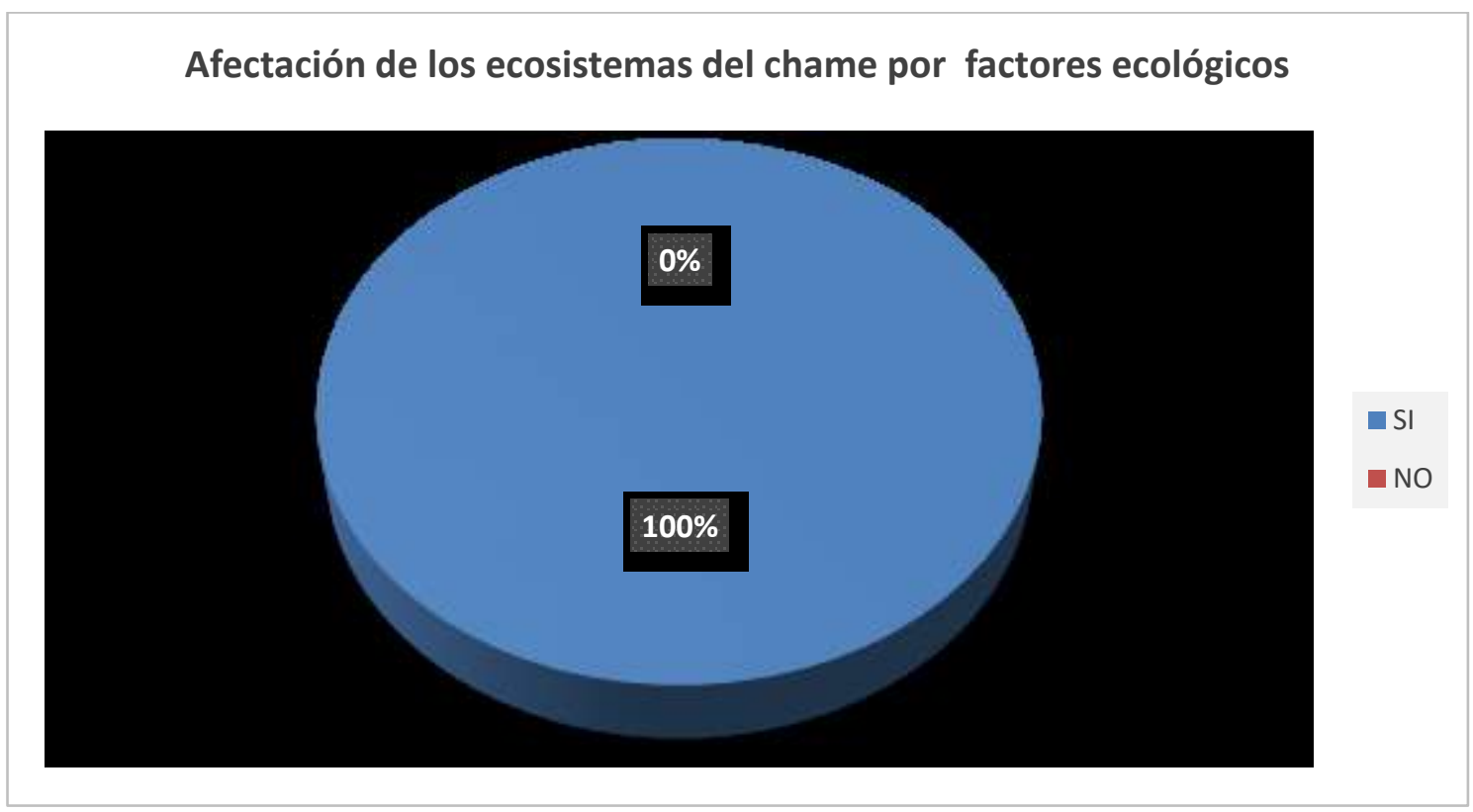

Fuente: Habitantes de la parroquia Canuto del cantón Chone.

Elaboración propia.

Analizado e interpretado los resultados según tabla $\mathrm{N}^{\circ} 5$ y grafico $\mathrm{N}^{\circ} 7$ de los 384 encuestados contestaron que si los ecosistemas del chame están siendo afectados por la variabilidad de los factores ecológicos que equivale al $100 \%$. Los resultados indican que la población es consciente que la variabilidad de los factores ecológicos si afectan a los ecosistemas del chame, debido a que han tenido que poner en veda la especie para su recuperación, detalle que anteriormente no era una preocupación para los que se dedican a la pesca de esta especie.

6. ¿Cree usted que debería haber algún control en la incidencia de los factores ecológicos en los ecosistemas del chame por parte de las autoridades competentes?

Tabla 6 Control de autoridades de los factores ecológicos en los ecosistemas del chame. 


\begin{tabular}{ccc}
\hline RESPUESTA & FRECUENCIA & PORCENTAJE \\
\hline SI & 380 & $100 \%$ \\
NO & 0 & $0 \%$ \\
TOTAL & 384 & $100 \%$ \\
\hline
\end{tabular}

Fuente: Habitantes de la parroquia Canuto del cantón Chone . Elaboración propia.

Gráfico 8 Control de autoridades de los factores ecológicos en los ecosistemas del chame.

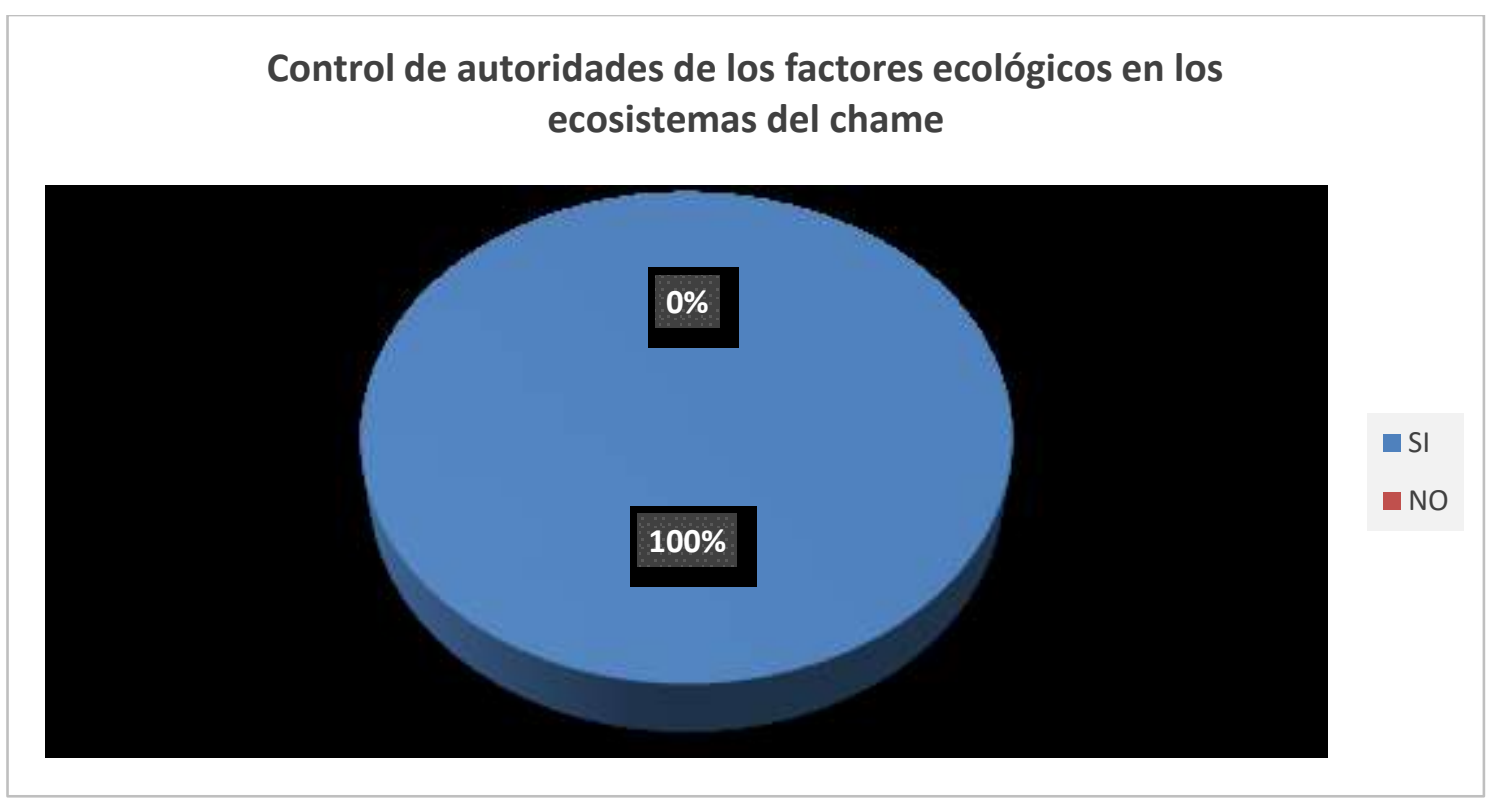

Fuente: Habitantes de la parroquia Canuto del cantón Chone.

Elaboración propia.

Una vez analizado e interpretado los resultados según tabla $\mathrm{N}^{\circ} 6$ y grafico $\mathrm{N}^{\circ} 8$ de los 384 encuestados el $100 \%$ manifestaron que si es necesario que se realicen controles por parte de las autoridades competentes. Conforme al resultado que se obtuvieron, se denota la necesidad de que las autoridades competentes deben controlar los diversos factores que influyen en el ecosistema del humedal. 
Tabla 7 Promedios diarios de temperatura y $\mathrm{Ph}$.

\begin{tabular}{|c|c|c|}
\hline FECHA & Promedio pH & Promedio Temperatura \\
\hline 02/10/2017 & 9,02 & $31,3^{\circ} \mathrm{C}$ \\
\hline 05/10/2017 & 9,06 & $31,5^{\circ} \mathrm{C}$ \\
\hline 09/10/2017 & 9,02 & $31,2^{\circ} \mathrm{C}$ \\
\hline $12 / 10 / 2017$ & 8,84 & $29,9^{\circ} \mathrm{C}$ \\
\hline $16 / 10 / 2017$ & 9,00 & $30,5^{\circ} \mathrm{C}$ \\
\hline $19 / 10 / 2017$ & 9,01 & $31,2^{\circ} \mathrm{C}$ \\
\hline 23/10/2017 & 9,05 & $31,4^{\circ} \mathrm{C}$ \\
\hline 26/10/2017 & 8,89 & $30,5^{\circ} \mathrm{C}$ \\
\hline 30/10/2017 & 9,04 & $31,5^{\circ} \mathrm{C}$ \\
\hline 04/11/2017 & 9,01 & $31,0^{\circ} \mathrm{C}$ \\
\hline $06 / 11 / 2017$ & 8,79 & $29,7^{\circ} \mathrm{C}$ \\
\hline 09/11/2017 & 8,81 & $29,8^{\circ} \mathrm{C}$ \\
\hline 13/11/2017 & 9,05 & $31,4^{\circ} \mathrm{C}$ \\
\hline $16 / 11 / 2017$ & 9,02 & $31,1^{\circ} \mathrm{C}$ \\
\hline 20/11/2017 & 9,06 & $31,6^{\circ} \mathrm{C}$ \\
\hline 23/11/2017 & 9,06 & $31,7^{\circ} \mathrm{C}$ \\
\hline 27/11/2017 & 9,04 & $31,4^{\circ} \mathrm{C}$ \\
\hline $30 / 11 / 2017$ & 9,02 & $31,3^{\circ} \mathrm{C}$ \\
\hline
\end{tabular}

Fuente: Investigación de campo.

Elaboración propia.

Gráfico 9 Promedios diarios de $\mathrm{pH}$ del humedal La Segua

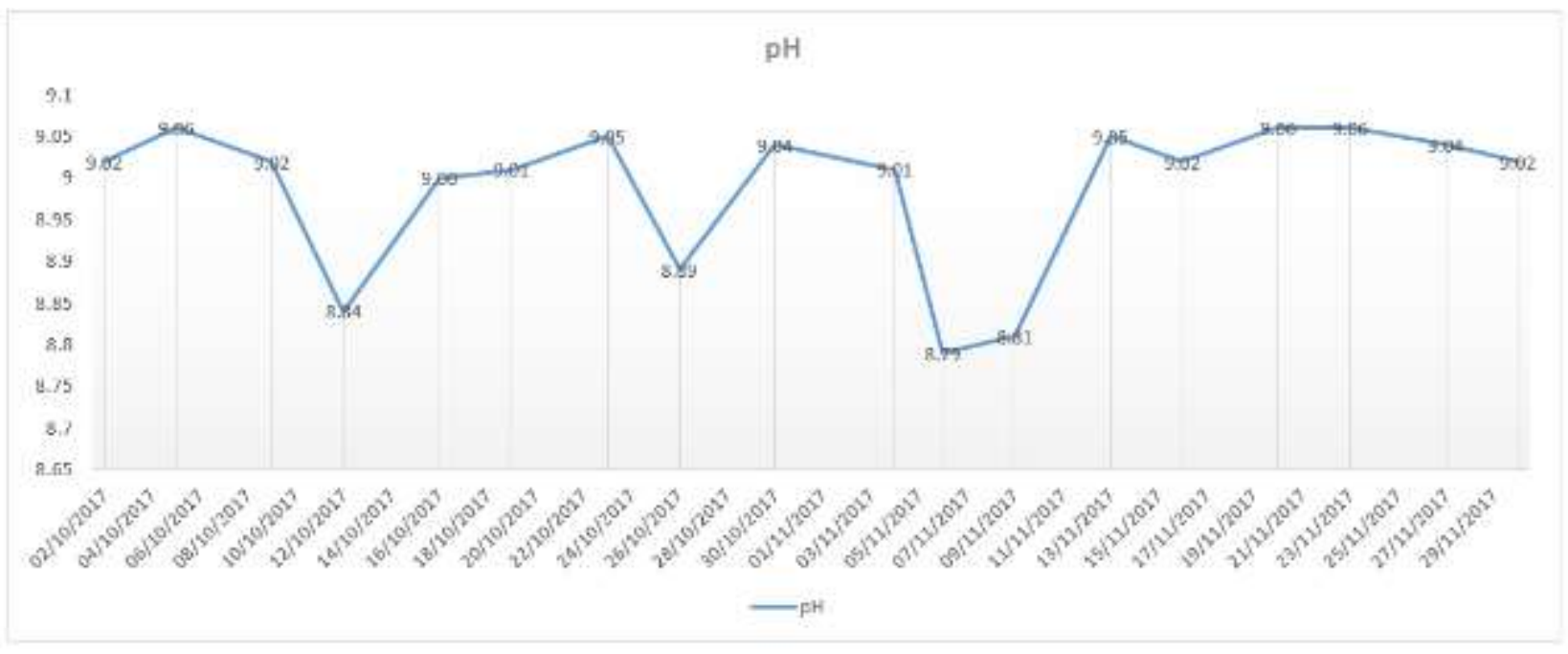

Fuente: Investigación de campo.

Elaboración propia. 
Una vez analizado e interpretado los resultados según tabla $\mathrm{N}^{\circ} 7$ y grafico $\mathrm{N}^{\circ} 9$ de las muestras de pH en los días seleccionados durante los dos meses para la investigación, en donde el valor promedio más alto corresponde a 9,06 siendo mayor a 9 que es el límite máximo permisible y el valor promedio más bajo es de 8,79 lo que indica que se tiene un $\mathrm{pH}$ alcalino o básico y que está acorde al valor del límite máximo permisible de acuerdo a lo indicado por Rodríguez (1994)

Gráfico 10 Promedios diarios de Temperatura del humedal La Segua.

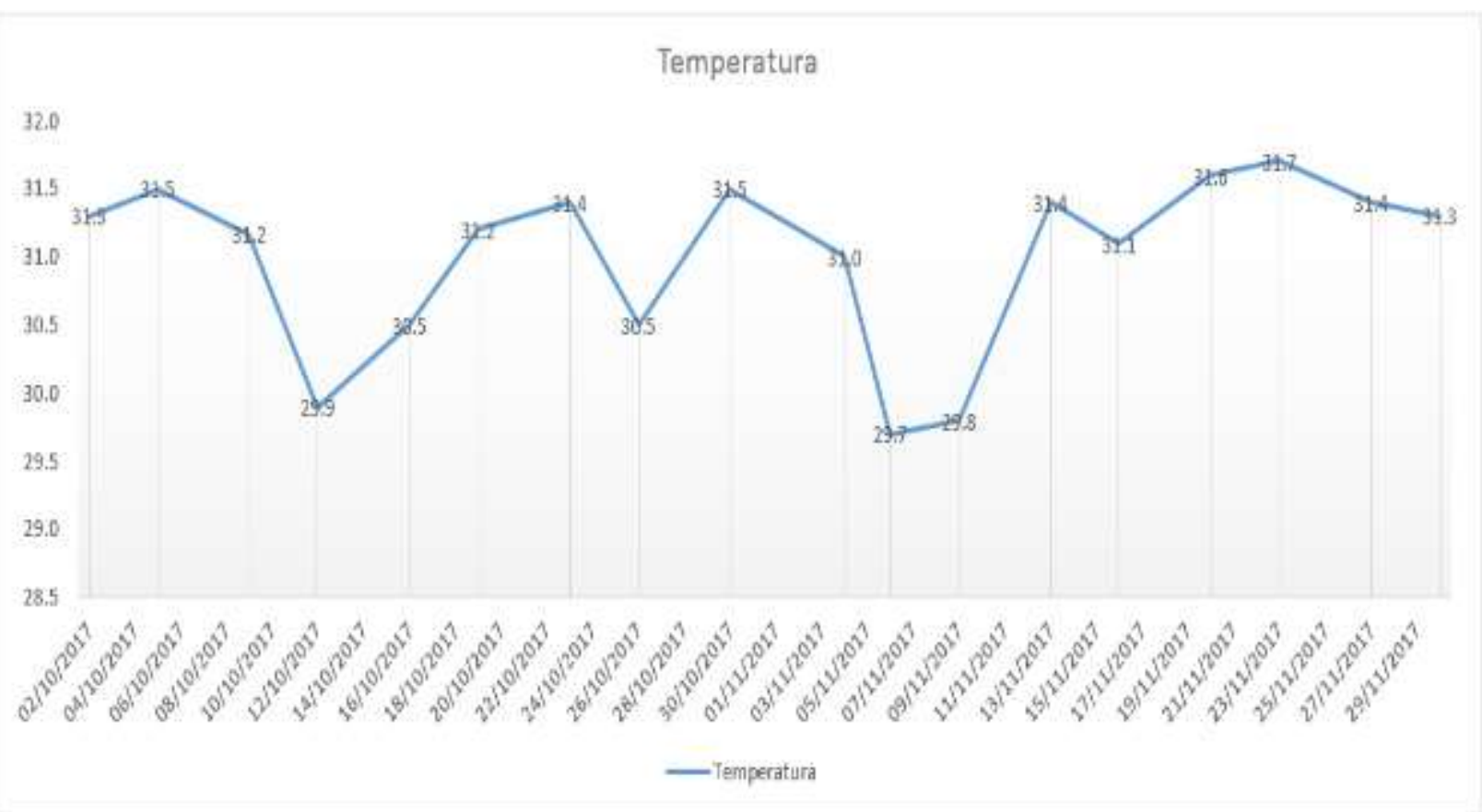

Fuente: Investigación de campo.

Elaboración propia.

Analizado e interpretado los resultados según tabla $\mathrm{N}^{\circ} 7$ y grafico $\mathrm{N}^{\circ} 10$ de las muestras de temperatura en los días seleccionados durante los dos meses para la investigación, en donde el día con el valor promedio más alto de temperatura corresponde a $31,7^{\circ} \mathrm{C}$ y el valor promedio más bajo corresponde a $29,7^{\circ} \mathrm{C}$ lo que indica que tienen un valor de temperatura superior al límite máximo permisible que es de $30^{\circ} \mathrm{C}$, según lo indicado por Nava (2008). 
Tabla 8 Identificación de Impactos Ambientales

\begin{tabular}{|c|c|c|c|c|c|c|c|c|c|c|c|c|}
\hline \multirow[t]{2}{*}{ ACTIVIDAD } & \multirow{2}{*}{$\begin{array}{l}\text { ASPECTO } \\
\text { AMBIENTAL }\end{array}$} & \multirow{2}{*}{$\begin{array}{c}\text { IMPACTO } \\
\text { AMBIENTAL }\end{array}$} & \multicolumn{3}{|c|}{$\begin{array}{c}\text { ANALISIS } \\
\text { PRIMARIO }\end{array}$} & \multicolumn{3}{|c|}{ ANÁLISIS REGLAMENTARIO } & \multicolumn{3}{|c|}{$\begin{array}{l}\text { ANÁLISIS } \\
\text { TECNICO }\end{array}$} & \multirow{2}{*}{$\begin{array}{c}\text { SIGNIFICANCIA } \\
\text { RESULTADOS } \\
\end{array}$} \\
\hline & & & ST & IC & $\mathrm{CL}$ & LG & DC & PI & $\mathrm{AC}$ & FC & AT & \\
\hline \multirow{4}{*}{$\begin{array}{l}\text { FACTORES } \\
\text { ECOLÓGICOS EN } \\
\text { LOS ECOSISTEMAS } \\
\text { DEL CHAME } \\
\text { (Dormitator latifrons) }\end{array}$} & $\begin{array}{l}\text { Proliferación r } \\
\text { lechuguines } \\
\text { crassipes, jacinto de agua) }\end{array}$ & $\begin{array}{l}\text { Poca oxigenación del } \\
\text { agua }\end{array}$ & NR & $\mathrm{D}$ & A & & $\mathrm{N}$ & $\mathrm{S}$ & 2 & 2 & 4 & $\mathrm{~S}$ \\
\hline & $\begin{array}{l}\text { Descarga de desechos } \\
\text { agrícolas, ganaderos y } \\
\text { chameras }\end{array}$ & $\begin{array}{l}\text { Cambios en el } \mathrm{pH} \text { del } \\
\text { agua }\end{array}$ & $\mathrm{R}$ & $\mathrm{D}$ & A & \begin{tabular}{|l} 
Ley de prevención y \\
control de \\
contaminación \\
ambiental la \\
\end{tabular} & $\mathrm{S}$ & $\mathrm{S}$ & 2 & 3 & 6 & $\mathrm{~S}$ \\
\hline & $\begin{array}{l}\text { Introducción de especies } \\
\text { foráneas (tilapia) }\end{array}$ & $\begin{array}{l}\text { Disminución y } \\
\text { destrucción del hábitat }\end{array}$ & $\mathrm{R}$ & $\mathrm{D}$ & A & \begin{tabular}{|l} 
Ley de prevención \\
control de \\
contaminación \\
ambiental la
\end{tabular} & $\mathrm{N}$ & $\mathrm{S}$ & 2 & 3 & 6 & $\mathrm{~s}$ \\
\hline & $\begin{array}{l}\text { Aumento de la } \\
\text { temperatura delambiente }\end{array}$ & $\begin{array}{l}\text { Aumento de la } \\
\text { temperatura del agua }\end{array}$ & $\mathrm{R}$ & $\mathrm{D}$ & A & $\begin{array}{l}\text { Ley de prevención y } \\
\text { control de } \\
\text { contaminación } \\
\text { ambiental }\end{array}$ & $\mathrm{N}$ & $\mathrm{s}$ & 2 & 3 & 6 & $\mathrm{~S}$ \\
\hline
\end{tabular}

\begin{tabular}{|l|l|l|}
\hline \multicolumn{1}{|c|}{ ANÁLISIS PRIMARIO } & \multicolumn{1}{|c|}{ ANÁLSIS REGLAMENTARIO } & \multicolumn{1}{|c|}{ ANÁLISIS TÉCNICO } \\
\hline $\begin{array}{l}\text { ST = SITUACIÓN: R (Rutinaria) N (No rutinaria) E } \\
\text { (Emergercia) }\end{array}$ & LG=LEGISLACIÓN & AC = ALCANCE: (1)Puntual (2)Loca1 (3) Regiona1 \\
\hline IC = INCIDENCIA: D (Directo) I (Indirecta) & $\begin{array}{l}\text { DC = DOCUMENTO CONTRATUAL S (Si) } \\
\text { N(No) }\end{array}$ & FC = FRECUENCIA: 1 (Esporádico) 2 (Ciclico) 3 (Continuo) \\
\hline CL = CLASE: B (Benefico) A (Adverso) & PARTES INTERESADAS: S (Si) N (No) & AT = ANÁLISIS TÉCNICO: (Producto de AC X FR) \\
\hline & & SIGNIFICANCIA: S ( Significativo) NS (No significativo) \\
\hline
\end{tabular}

\section{Fuente: Investigación de campo}

Elaboración propia

\begin{tabular}{|l|l|}
\hline Significativo & No Significativo \\
\hline
\end{tabular}

De acuerdo con el resultado de la investigación de campo realizada y plasmada en la tabla $\mathrm{N}^{\circ} 8$ de Identificación de impactos ambientales existen varios aspectos a considerar que afectan a los factores ecológicos en el ecosistema del chame, el primer factor es la proliferación de lechuguinos (Eichhornia crassipes, jacinto de agua) en época invernal, la cual cuando existe en exceso provoca que la oxigenación del agua sea escaza, produciendo así afectación al ecosistema del humedal.

Otro factor a considerar son los desechos de las actividades agrícolas, ganaderos y chameras que se realizan en las cercanías de La Segua, la cual es recurrente con una frecuencia continua y afecta los niveles de $\mathrm{pH}$ del agua del humedal. La introducción de especies foráneas en este caso de la Tilapia ha hecho que disminuya y se destruya el hábitat natural del humedal, además esta especie es depredadora del chame lo que lo convierte en un problema para la especie nativa. Por último el aumento de la temperatura general la cual en época invernal se hace más latente hace que la temperatura del agua del humedal este en rangos que afecta el hábitat natural del chame. 
Todos los resultados indican que la temperatura y pH del humedal están siendo afectadas de manera continua y de no controlar estos la afectación será mucho mayor, esto se ve reflejado en el resultado del análisis técnico que arroja resultados de 4 para la poca oxigenación, y de 6 a los cambios del $\mathrm{pH}$, disminución del habitad y aumento de la temperatura del agua del humedal. La significancia de cada impacto ambiental queda plasmada como significativo para cada aspecto, como lo se puede observar con color verde en la tabla $\mathrm{N}^{\circ} 8$.

\section{Conclusiones.}

- El humedal La Segua es un ecosistema que se torna importante para el desarrollo social y económico de quienes habitan en sus alrededores, pues es una fuente significa de ingresos derivados de la cría y pesca de chame, además de las actividades turísticas que se pueden desarrollar en la zona por la fauna y flora existente; sin embargo estas actividades generan impactos en los factores ecológicos del ecosistema del chame, los mismos que se identificaron durante el desarrollo de esta investigación.

- Entre los factores ecológicos más importantes del humedal La Segua para el desarrollo de la vida del chame se encuentran la temperatura y el $\mathrm{pH}$, los cuales deben encontrarse a un promedio de entre 21 y $30^{\circ} \mathrm{C}$ el primero; y de 6,4 a 9,4 el segundo para que el crecimiento y reproducción de esta especie sea óptimo y se dé de manera natural; pero cabe destacar que la influencia de las acciones del hombre en esta zona, como la introducción de alimento balanceado por ejemplo y las repercusiones indirectas generadas por los cambios climáticos; generan cambios en los valores normales de estos factores, forzando a la especie a adaptarse a los cambios constantes y reduciendo su calidad y población.

- Los análisis de las muestras tomadas en el humedal durante 28 días demostraron que el nivel de $\mathrm{pH}$ se encontró dentro del rango promedio óptimo; mientras que la temperatura se encontró en niveles ideales antes mencionados únicamente en tres días. Cabe recalcar que en el resto de los días en el que se realizaron los análisis, para la temperatura los resultados sobrepasaron el rango promedio óptimo para el ecosistema del chame, lo cual demuestra que tanto el desarrollo de las actividades económicas como los cambios climáticos que se generan en la zona tienen un impacto negativo en el ecosistema del chame y que, por lo tanto, en el largo plazo esto podría conllevar a su deterioro y posterior desaparición.

- A más de lo mencionado, gracias a esta investigación se pudo determinar que a pesar de que la población sujeta a estudio está consciente de que sus actividades afectan el desarrollo efectivo del ciclo de vida del chame en su propio ecosistema, no están dispuestos a dejar de realizarlas o a moderar su recurrencia, pues constituyen para ellos una fuente significativa de ingresos; por lo que se hace evidente la necesidad de plantear una propuesta que conlleve a contrarrestar la problemática identificada, la misma que estará basada en el establecimiento de un plan de control de los factores ecológicos de los ecosistema del chame en La Segua de Canuto del cantón Chone y que implicará la acción conjunta entre habitantes y autoridades del cantón para el incremento de conocimientos y la generación de una cultura de conservación y cuidado del humedal más concientizado y efectivo.

\section{Agradecimientos.}

- Agradecemos a las autoridades de la Universidad Estatal del Sur de Manabí (UNESUM), por el apoyo en esta investigación. 


\section{Referencias bibliográficas.}

- Arteaga Sabando, E. (2012). La contaminación de la ciénaga "La Segua", la pérdida de su flora - fauna y propuesta educativa. Obtenido de repositorio.ute.edu.ec: http://repositorio.ute.edu.ec/bitstream/123456789/2853/1/52644_1.pdf

- EcoCostas. (2006). Galeria de Imagenes - Chame. Obtenido de http://success.ecocostas.org/success/index.php/galeria-de-imagenes/category/1

- GAD Parroquial Canuto. (05 de 2015). Diagnostico Plan de ordenamiento Territorial. Obtenido de http://app.sni.gob.ec: http://app.sni.gob.ec/sni-

link/sni/PORTAL_SNI/data_sigad_plus/sigadplusdiagnostico/1360044680001_PDYOT\%20CA NUTO-\%20CHONE-\%20MANABI_15-05-2015_19-44-37.pdf

- Gavino Arias, E. (2017). Revisión acerca de la utilización de microorganismos en el mejoramiento de sedimentos en granjas camaroneras. Obtenido de http://repositorio.utmachala.edu.ec: http://repositorio.utmachala.edu.ec/bitstream/48000/10512/1/DE00002_EXAMENCOMPLEXI VO.pdf

- Gobierno Provincial de Manabí. (2016). Chone. Obtenido de manabi.gob.ec: http://www.manabi.gob.ec/cantones/chone

- Haz, M. (05 de enero de 2002). Proyecto de produccion y exportación del chame como nueva alternativa comercial del Ecuador. Obtenido de dspace.espol.edu.ec: https://www.dspace.espol.edu.ec/bitstream/123456789/521/1/955.pdf

- Instituto Geográfico Nacional. (s.f.). Suelos. Obtenido de campus.usal.es: http://campus.usal.es/ geografia/PDFsgeografiayensenanzasmedias/Mapasuelos_EspanaIGN.pd $\mathrm{f}$

- Jiménez Marmolejo, V., \& Espín Novoa, J. (2010). Plan de negocios para la creación de un criadero especializado en el cultivo y comercialización de chame ubicado en la provincia de Esmeraldas cantón Río Verde. Obtenido de repositorio.puce.edu.ec: http://repositorio.puce.edu.ec/bitstream/handle/22000/3136/T-PUCE-3493.pdf;sequence=1

- Lascano Freire, C. (2000). Experiencias en el manejo del Chame (Dormitator latifrons) en la Cuenca del Río Guayas, Ecuador. Obtenido de udenar.edu.co: revistas.udenar.edu.co/index.php/reipa/article/download/1476/1816

- Ministerio del Ambiente. (2015). Humedales del Ecuador: La Segua. Obtenido de suia.ambiente.gob.ec: http://suia.ambiente.gob.ec/web/humedales/la-segua

- Ministerio del Ambiente del Ecuador. (2015). LA SEGUA. Obtenido de http://suia.ambiente.gob.ec: http://suia.ambiente.gob.ec/web/humedales/la-segua

- Ministerio del Ambiente. (s.f.). Manabi, hogar de bellos humedales. Obtenido de http://www.ambiente.gob.ec: http://www.ambiente.gob.ec/manabi-hogar-de-bellos-humedales/ 
- Nava, J. (2008). Evaluación de Bacterias Ácido Lácticas Comercializadas como Probióticas. Merida: Universidad de los Andes. Departamento de Biología.

- Ortega Granda, J. (octubre de 2016). Análisis del comercio internacional del Chame (Dormitator latifrons, richardson, 1844) y su impacto sobre sus poblaciones silvestres en el Ecuador: Propuesta de inclusión en CITES. Obtenido de repositorio.ug.edu.ec:http://repositorio.ug.edu.ec/bitstream/redug/25242/1/Tesis\%20Chame\%20 6Rf.pdf

- Richardson. (1844).

- Rodríguez Montes de Oca, G., Medina Hernández, E., Velázquez Sandoval, J., López López, V., Román Reyes, J., Dabrowski, K., \& Haws, M. (2012). Producción de larvas de Chame (Dormitator latifrons, Pisces: Eleotridae) usando GnRHa and LHRHa. Revista Colombiana de Ciencias Pecuarias, 422-429.

- Rodriguez, M. (1994). Bacterias productoras de acido láctico: efectos sobre el crecimiento y la flora intestinal de pollos, gazapos y lechones. Universidad Complutense de Madrid. En M. Rodriguez. Madrid: Facultad de Veterinaria.

- Rodríguez, M. C. (2010). Humedales. Obtenido de Scribd.com: https://es.scribd.com/document/276992570/Humedales

- Sandoval, E., Madrigal, X., Escalera, L., \& Medina, M. (2014). Estructura de la comunidad de peces en cuatro estuarios del Pacífico mexicano central. Revista Mexicana de Biodiversidad 85, 1184-1196.

- Toapanta Trujillo, I. (enero de 2012). Estudio investigativo del chame, sus usos y su aplicación en gastronomía. Obtenido de repositorio.ute.edu.ec: http://repositorio.ute.edu.ec/bitstream/123456789/11767/1/50914_1.pdf

- Valarezo, G., \& Quevedo, O. (2009). Ficha Informativa de los Humedales de Ramsar (FIR). Obtenido de http://suia.ambiente.gob.ec:

http://suia.ambiente.gob.ec/documents/783967/889253/Ficha+Ramsar+Ci\%C3\%A9naga+La+Se gua.pdf/1461f766-e79f-4d39-81f9-a2e3c308c112

- Zambrano, G. (octubre de 2014). Análisis de la producción y comercialización del Chame (Dormitator latifrons) en el Ecuador: provincia de Manabi cantón Chone periodo 2010-2013. Obtenido de http://repositorio.ug.edu.ec/: http://repositorio.ug.edu.ec/bitstream/redug/9623/1/TESIS\%20COMPLETA.pd

\section{LC Ciencia}




\section{Para citar el artículo indexado.}

Osejos M., Merino M., Jaramillo J \& Merino M. (2018). Factores ecológicos y su incidencia en los ecosistemas del chame (dormitator latifrons) en la segua de canuto cantón chone ecuador. Revista electrónica Ciencia Digital 2(2), 8-18. Recuperado desde:

http://www.cienciadigital.org/index.php/CIENCIADIGITAL/article/view/67/Publicacion1 $\% 2 \mathrm{CNo} 2 \% 2 \mathrm{CVol} 1$

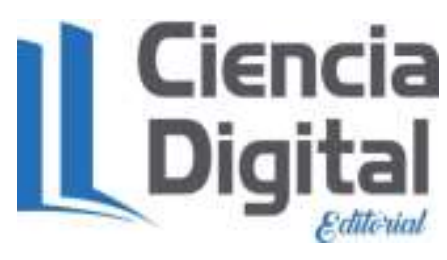

El artículo que se publica es de exclusiva responsabilidad de los autores y no necesariamente reflejan el pensamiento de la Revista Ciencia Digital.

El articulo queda en propiedad de la revista y, por tanto, su publicación parcial y/o total en otro medio tiene que ser autorizado por el director de la Revista Ciencia Digital.
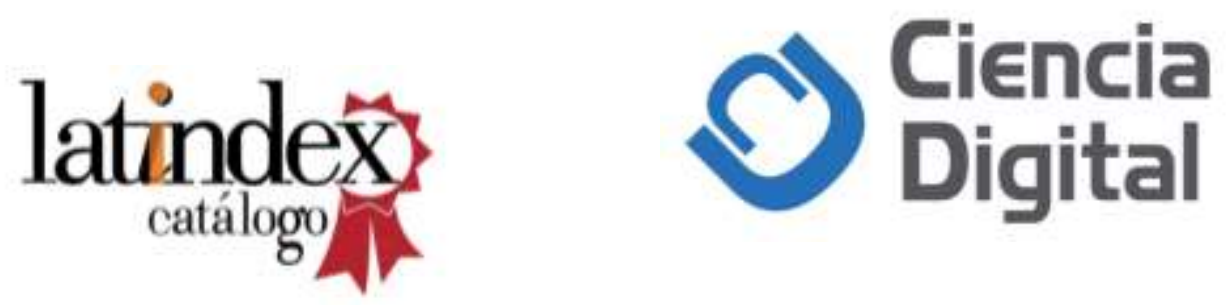